\title{
ESPERMATOGÊNESE EM Callichirus major (CRUSTACEA: AXIIDEA)
}

\section{Tugstênio Lima de Souza ${ }^{1}$ \\ Adriane Araújo Braga² \\ Erika Takagi Nunes ${ }^{3}$}

Resumo: Callichirus major pertence à ordem Decapoda e família Callianassidae, sendo uma espécie que habita a região interdial de ecossistemas praianos, sendo amplamente capturada para utilização como isca viva para pesca. O presente estudo objetivou descrever morfologicamente o processo espermatogênico nesta espécie de crustáceo, com a finalidade de entender melhor a sua biologia reprodutiva. Os animais, coletados ao longo da Praia do Corujão, em Piúma/ES, foram triados e, em laboratório, tiveram suas gônadas masculinas dissecadas e submetidas ao processamento histológico de rotina. As células germinativas foram classificadas em: Espermatogônia (SPG); Espermatócito l e II (SPTCI, SPTCII); Espermátide inicial e final (El, EF) e Espermatozoide (SPZ). Células acessórias também estiverem presentes, possuindo núcleo esférico ou triangular, distribuídas na periferia e entre a linhagem germinativa no lóbulo gonadal. Baseado nas observações microscópicas foi possível constatar que esta espécie possui a espermatogênese assincrônica, indicando que a reprodução pode ocorrer durante o ano todo.

Palavras-chave: Reprodução; Histologia; Corrupto; Decapoda; Gametogênese.

\footnotetext{
${ }^{1}$ Ciências Biológicas/Universidade Federal do Espírito Santo, Brasil. E-mail: tugstenio94@hotmail.com.

2 Ciências Biológicas/Universidade Federal do Espírito Santo, Brasil. E-mail: dricrab@yahoo.com.br.

${ }^{3}$ Ciências Biológicas/Universidade Federal do Espírito Santo, Brasil. E-mail: erikatnunes@yahoo.com.br.
} 